\title{
Simvastatin modulates the adhesion and growth of hepatocellular carcinoma cells via decrease of integrin expression and ROCK
}

\author{
BORNA RELJA ${ }^{1}$, FRANK MEDER ${ }^{1}$, MINHONG WANG $^{1}$, ROMAN BLAHETA ${ }^{2}$, \\ DIRK HENRICH ${ }^{1}$, INGO MARZI ${ }^{1}$ and MARK LEHNERT ${ }^{1}$ \\ Departments of ${ }^{1}$ Trauma Surgery and ${ }^{2}$ Urology, Johann Wolfgang Goethe University, \\ Frankfurt am Main, Germany
}

Received October 1, 2010; Accepted November 29, 2010

DOI: $10.3892 /$ ijo.2010.892

\begin{abstract}
Hepatocellular carcinoma (HCC) has become a global health concern and is one of the leading causes of cancer death after lung and gastric cancers. It has been suggested that the 3-hydroxy-3-methyl-glutarylcoenzymeCoA (HMG-CoA) reductase inhibitor simvastatin exhibits anticancer properties. To this end, we analyzed the influence of simvastatin on the cell growth and adhesion of HCC and evaluated the yet poorly characterized mechanism of action of simvastatin in HCC. HepG2 and Huh7 cells were treated with simvastatin $(16-64 \mu \mathrm{M})$ for different time periods. Cell proliferation using the MTT assay and tumor cell adhesion to endothelial cell monolayers were evaluated. $\beta 1, \beta 3$ and $\alpha 2$ integrin adhesion receptors and the downstream target of simvastatin Rho-dependent kinase (ROCK) were analyzed by Western blot. Further blocking studies with the ROCKinhibitor H1152 and anti-integrin $B 1$ and $B 3$ antibodies were carried out. Simvastatin treatment inhibited dose-dependently tumor cell growth and attachment to endothelium. The inhibitory effect of simvastatin on cell adhesion was associated with decreased expression of $\beta 1, \beta 3$ and $\alpha 2$ integrins. Furthermore, simvastatin strongly reduced the expression of ROCK-I and activated MYPT, an indicator of ROCK activity. Also, the ROCK-inhibitor H1152 reduced the adhesive capacity of the tumor cells. Anti-adhesive effects of simvastatin were prevented by exogenous mevalonate, a downstream product of HMG-CoA. Tumor cell adhesion to endothelium was significantly impaired following incubation with functional anti- $\beta 1$ antibody. Simvastatin modifies the expression of cell adhesion molecules leading to reduced tumor cell growth and invasion. These beneficial effects of simvastatin may be mediated by ROCK. The data presented may point to novel treatment options for HCC.
\end{abstract}

Correspondence to: Dr Borna Relja, Department of Trauma, Hand and Reconstructive Surgery, Hospitals of the GoetheUniversity Frankfurt am Main, 60590 Frankfurt, Germany

E-mail: info@bornarelja.com

Key words: cancer, liver, simvastatin, integrins, ROCK, adhesion

\section{Introduction}

Hepatocellular carcinoma (HCC) is one of the most common malignancies and causes of cancer death worldwide (1-3). It is characterized by a poor prognosis due to a high potential for metastasis and recurrence within a short time $(4,5)$. Simvastatin, a 3-hydroxy-3-methylglutaryl coenzyme A (HMG-CoA) reductase inhibitor, is a widely used and well tolerated drug for treating hypercholesterolemia, coronary heart disease and stroke (6). Mevalonate biosynthesis is catalyzed by HMG-CoA reductase (6). Simvastatin reduces the synthesis of mevalonate by inhibiting HMG-CoA reductase finally leading to the blockade of Rho GTPases with their effector proteins ROCK $(7,8)$. Since ROCK is involved in tumor cell migration, invasion and spreading, it is suggested that downregulation of these proteins by simvastatin may reduce tumor cell proliferation, apoptosis and dissemination (8-10). Indeed, novel reports demonstrate that simvastatin treatment exerts further anticancer effects in several human malignancies, including breast, colon and prostate cancer (11-13).

Given the need for alternative options, these findings and the limited knowledge about the simvastatin effects on HCC prompted us to evaluate its potential therapeutic options for HCC. Therefore, we analyzed the cell growth and adhesion capacity after simvastatin treatment in HepG2 and Huh7 cell lines. The expression pattern of integrin subunits was further evaluated by Western blot and correlated with tumor cell growth and adhesion to an endothelial cell monolayer.

Integrins comprise the major class of cell surface receptors mediating cell-cell and cell-extracellular matrix (ECM) interactions (14). Integrins are a large family of heterodimeric transmembrane receptors composed of $\alpha$ and $\beta$ subunits (14). Alterations in integrin expression are known to mediate tumor cell migration and adherence to the endothelium of the capillary bed of the target organ and tumor cell proliferation.

Blocking studies using the functional anti-integrin antibodies evaluated the relevance of integrin $\beta 1$ for adhesive capacity of tumor cells in our model. Furthermore, we explored the molecular mechanism responsible for the anticancer effects of simvastatin by inhibition of the ROCK pathway in $\mathrm{HCC}$.

We concluded from these findings that simvastatin may profoundly decrease tumor cell growth and reduce tumor cell 
adhesion to endothelium by reducing the expression of integrins $\beta 1, \beta 3$ and $\alpha 2$. We also demonstrated that simvastatin inhibits the ROCK pathway which has prominent effects on the tumor cell growth and adhesion. Taken together, these data suggest that simvastatin may provide a therapeutic advantage for $\mathrm{HCC}$ treatment but this requires further evaluation.

\section{Materials and methods}

Cell cultures. Human HCC cell lines HepG2 and Huh7 were purchased from Cell Line Services (Heidelberg, Germany). Tumor cells were maintained at $37^{\circ} \mathrm{C}$ under $5 \% \mathrm{CO}_{2}$ in RPMI-1640 medium (Seromed, Berlin, Germany) supplemented with $10 \%$ heat-inactivated fetal calf serum (FCS), $100 \mathrm{IU} / \mathrm{ml}$ penicillin and $100 \mu \mathrm{g} / \mathrm{ml}$ streptomycin (Gibco, Karlsruhe, Germany) and $20 \mathrm{mM}$ HEPES buffer (Sigma, Steinheim, Germany).

Endothelial cells (HUVECs) were isolated from human umbilical veins and harvested by enzymatic treatment with dispase (Sigma, Taufkirchen, Germany). HUVECs were maintained in Medium 199 (Gibco) supplemented with 10\% FCS, $10 \%$ pooled human serum (Blood Bank of The German Red Cross, Frankfurt am Main, Germany), $20 \mu \mathrm{g} / \mathrm{ml}$ endothelial cell growth factor (Roche, Mannheim, Germany), $5 \mathrm{U} / \mathrm{ml}$ heparin (Roche), $100 \mathrm{ng} / \mathrm{ml}$ gentamycin (Gibco) and $20 \mathrm{mM}$ HEPES (Seromed). HUVECs were grown in a humidified $5 \% \mathrm{CO}_{2}$ incubator at $37^{\circ} \mathrm{C}$. The purity of isolated HUVEC cultures was controlled by staining with fluorescein isothiocyanate (FITC)-labelled monoclonal antibody against Factor VIII-associated antigene (Von Willebrand factor; clone F8/86; Dako, Hamburg, Germany; FL-1H (log) channel histogram analysis; $1 \times 10^{4}$ cells/scan) and analyzed by FACScan (Becton-Dickinson, Heidelberg, Germany) or microscopically. Only cell cultures with a purity of $>95 \%$ were utilized for experimental use. Cells were used between passages 2 and 4 .

Drug and antibody treatment. Simvastatin was obtained from Calbiochem (Darmstadt, Germany) and activated prior to the experiments by alkaline hydrolysis of the lactone moiety according to the manufacturer's protocol. Tumor cells were treated for 24,48 and $72 \mathrm{~h}$ with various concentrations of simvastatin $(0-64 \mu \mathrm{M})$ or with vehicle with fresh changes of culture medium and simvastatin after $48 \mathrm{~h}$.

In additional experiments, mevalonate (3.2 mM; Sigma) was added to the medium containing simvastatin to address the simvastatin site of action along the mevalonate pathway. To confirm the involvement of specific pathways, the highly selective Rho-kinase inhibitor H1152 (1 $\mu \mathrm{M}$; Calbiochem) was added to the medium instead of simvastatin.

Functional analysis of integrins $\beta 1$ and $\beta 3$ was performed by incubation of tumor cells with human anti- $\beta 1(10 \mu \mathrm{g} / \mathrm{ml}$; R\&D Biosciences, Wiesbaden, Germany) or anti- $\beta 3$ (Millipore, Schwalbach, Germany) antibody for $60 \mathrm{~min}$. Thereafter, cells were applied for adhesion to endothelial monolayer.

Tumor cell growth. Cell Proliferation Kit I (3-(4,5-dimethylthiazol-2-yl)-2,5-diphenyltetrazolium bromide, MTT; Roche Diagnostics, Penzberg, Germany) was used to evaluate MTTreducing activity of the cellular mitochondria. HepG2 and
Huh7 cells $\left(100 \mu 1,1 \times 10^{4} / \mathrm{ml}\right)$ were seeded onto 96-well tissue culture plates and incubated with simvastatin or vehicle (ctrl) as described above to monitor dose-response. MTT $(0.5 \mathrm{mg} / \mathrm{ml})$ was added to each well $24 \mathrm{~h}$ before the evaluation of each time-point, and the cells were incubated for $4 \mathrm{~h}$ at $37^{\circ} \mathrm{C}$. Thereafter, cells were lysed in a solubilization solution containing $10 \%$ sodium dodecyl sulphate (SDS) in $0.01 \mathrm{M}$ hydrogen chloride $(\mathrm{HCl})$ and incubated overnight at $37^{\circ} \mathrm{C}$ in $5 \% \mathrm{CO}_{2}$. The following day the absorbance of each well was measured with a multimode microplate reader (Infinite M200; Tecan, Crailsheim, Germany) at $550 \mathrm{~nm}$. Each experiment was performed in triplicate. After substracting the background absorbance, results were expressed as mean cell number.

Monolayer adhesion assay. To analyze tumor cell adhesion, HUVECs were transferred to 6-well multiplates (Falcon Primaria; Becton-Dickinson) in complete HUVEC medium. When a confluency of $\sim 80 \%$ was reached, HepG2 and Huh7 cells were detached from the culture flasks by accutase (PAA Laboratories, Cölbe, Germany) and $0.5 \times 10^{6}$ cells were carefully added to the HUVEC monolayer for $60 \mathrm{~min}$. Subsequently, non-adherent tumor cells were washed off using warmed $\left(37^{\circ} \mathrm{C}\right)$ Medium 199. The remaining cells were fixed with $1 \%$ glutaraldehyde. Adherent cells were counted in five different fields of a defined size $\left(5 \times 0.25 \mathrm{~mm}^{2}\right)$ using a phase contrast microscope (x20 objective) and the mean cellular adhesion rate was calculated.

Western blot. Total integrin B1 (CD29), integrin B3 (CD61), integrin $\alpha 2$ (VLA-2 $\alpha$, CD49b), ROCK, MYPT and MYPT (phospho) content in HepG2 and Huh7 cells was evaluated by Western blot analysis using mouse anti-CD29, anti-human CD61, CD49b and mouse anti-ROCK-I (BD Pharmingen, Heidelberg, Germany), goat anti-MYPT1 and anti-p-MYPT1 (Thr 696; Santa Cruz Biotechnology, Santa Cruz, CA, USA). Tumor cell lysates (50 $\mu$ g protein) were separated by electrophoresis on $7 \%$ polyacrylamide SDS gels and transferred to nitrocellulose membranes (Amersham-Buchler, Braunschweig, Germany). Determination of $\beta$-actin with anti- $\beta$-actin antibody (Sigma) served as loading control. Blots were blocked (10\% non-fat dry milk in $1 \mathrm{mM}$ Tris, $150 \mathrm{mM} \mathrm{NaCl}$, $\mathrm{pH}$ 7.4) for $1 \mathrm{~h}$, incubated $1 \mathrm{~h}$ at RT with primary antibody (diluted according to manufacturer's instructions in blocking buffer with $0.5 \%$ Tween-20 and $0.5 \%$ bovine serum albumin) and then incubated $1 \mathrm{~h}$ with horseradish peroxidaseconjugated secondary antibody (Santa Cruz Biotechnology) diluted 1:1000 in blocking buffer with $0.5 \%$ Tween-20 and $0.5 \%$ bovine serum albumin at RT. Proteins were detected with ECL ${ }^{\mathrm{TM}}$ Western blot detection reagents (GE Healthcare, Munich, Germany) and visualized after exposure to X-ray film (Hyperfilm ${ }^{\text {TM }}$ ECTM, Amersham, Freiburg, Germany). The film was digitized, and the integrated density of individual bands was determined using the software Multianalyst (Biorad, Munich, Germany). By densitometric measurements using the same software the amount of protein expression was normalized to $\beta$-actin.

Statistical analysis. All experiments were performed 3-6 times. Differences between groups were determined by Wilcoxon 
A

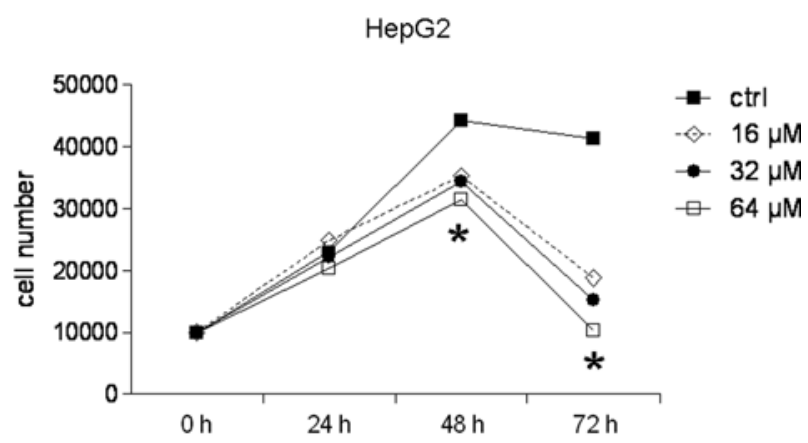

B

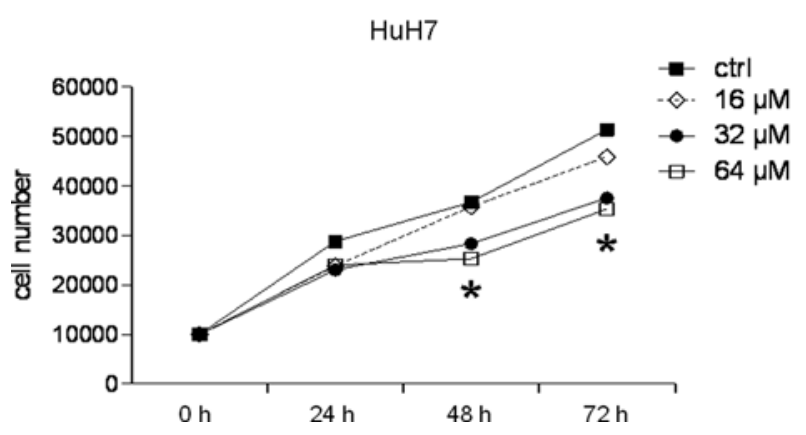

Figure 1. Effects of simvastatin on hepatocellular carcinoma cell proliferation HepG2 and Huh7 cells were treated with different doses of simvastatin (0$64 \mu \mathrm{M}$ ) for 24,48 and $72 \mathrm{~h}$ or remained untreated (ctrl). Then, cells were placed on a 96-well culture plate and cell proliferation was assessed using the 3-(4,5-dimethylthiazol-2-yl)-2,5-diphenyltetrazolium bromide (MTT) dye reduction assay. The assays were carried out in triplicate and data are given as the mean \pm SEM. Representative figure from one out of six experiments is shown ( ${ }^{*} \mathrm{p}<0.05 \mathrm{vs}$. ctrl).

Mann-Whitney U-test. $\mathrm{p}<0.05$ was considered significant. Data are given as mean \pm standard error of the mean (SEM).

\section{Results}

Simvastatin down-regulates tumor cell growth. Proliferation analysis revealed rapid cell growth of both HepG2 and Huh7 (Fig. 1). HepG2 cells demonstrated higher proliferative capacity than Huh7 cells. Both HCC cell lines showed significant reduction in cell proliferation following treatment with simvastatin in a dose- and time-dependent manner compared with controls (Fig. 1). However, HepG2 cells already responded to low dose of simvastatin $(16 \mu \mathrm{M})$, whereas Huh7 cells demonstrated inhibition of proliferation only at higher simvastatin concentrations (32 and $64 \mu \mathrm{M})$. A $48 \mathrm{~h}$ and particularly $72 \mathrm{~h}$ simvastatin pre-treatment evoked a stronger response than a $24 \mathrm{~h}$ pre-treatment in both HepG2 and Huh7 cell lines.

Simvastatin alters tumor cell adhesion to HUVECs. HepG2 and Huh7 cells were treated with 16, 32 and $64 \mu \mathrm{M}$ simvastatin for 24, 48 and 72 h to study the effect of simvastatin on adhesion to HUVECs. Fig. 2 shows the adhesion kinetics of treated versus non-treated cells. The initial attachment rate of control HepG2 cells to HUVECs was higher than the initial
A

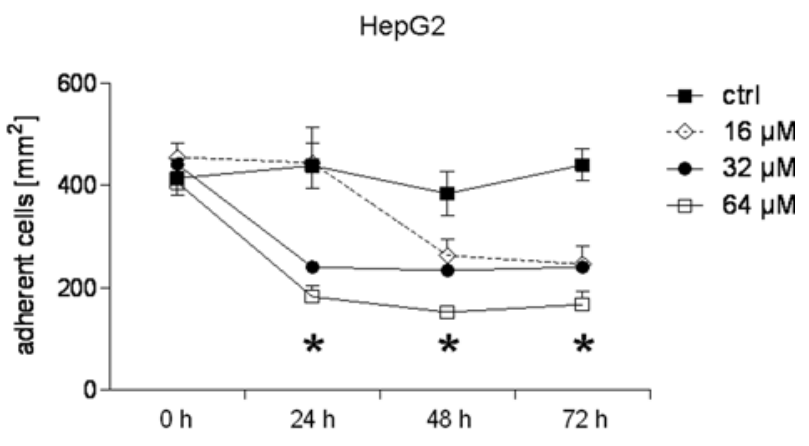

B

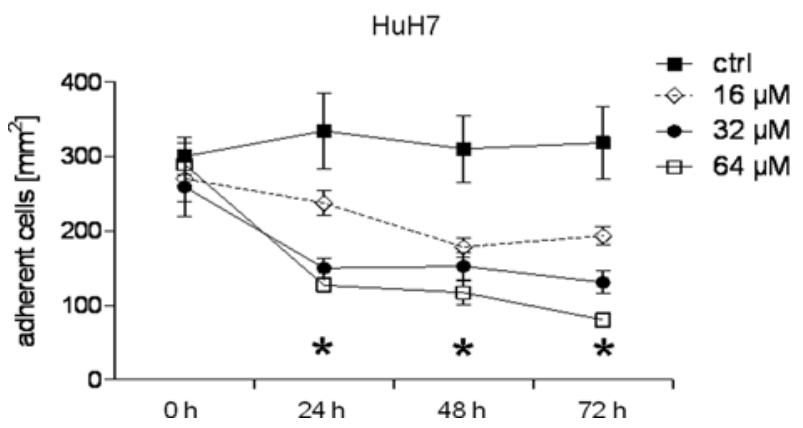

Figure 2. Adhesion capacity of HepG2 and Huh7 cells to HUVECs was down-regulated by simvastatin. HepG2 and Huh7 cells were treated with different doses of simvastatin $(0-64 \mu \mathrm{M})$ for 24,48 and $72 \mathrm{~h}$ or remained untreated (ctrl). Then, cells were added to HUVEC monolayers at a density of $0.5 \times 10^{6}$ cell/well for $60 \mathrm{~min}$. Non-adherent cells were washed off and adherent cells were fixed and counted in five different fields $\left(5 \times 0.25 \mathrm{~mm}^{2}\right)$ using a phase contrast microscopy. Data are given as the mean \pm SEM. Representative figure from one out of six experiments is shown $\left({ }^{*} \mathrm{p}<0.05\right.$ vs. ctrl).

attachment rate of control Huh7 cells to HUVECs. Simvastatin blocked significantly the adhesion of both HepG2 and Huh7 tumor cell lines to endothelium when it was applied for 48 or $72 \mathrm{~h}$ in all doses. A 24-h application of $16 \mu \mathrm{M}$ simvastatin did not prevent HepG2 cell attachment to HUVECs, whereas Huh7 cell adhesion to endothelium was markedly decreased compared to control cells. Generally, both cell lines were more sensitive to high doses (32 and $64 \mu \mathrm{M})$ of simvastatin compared to the $16 \mu \mathrm{M}$ simvastatin application.

To evaluate the effect and specificity of the inhibitory potential of simvastatin, cells were pre-treated with mevalonate in combination with simvastatin. This study was performed with the simvastatin dose of $32 \mu \mathrm{M}$ with a pre-treatment duration of $48 \mathrm{~h}$. Simvastatin reduced markedly tumor cell adhesion to endothelial cells. Significantly more cells attached to HUVECs when simvastatin was applied in combination with mevalonate (Fig. 3), although mevalonate alone did not influence the adhesion characteristics of HCC cells (data not shown). To confirm that the effect of simvastatin was mediated through Rho/Rho-kinases, we used the ROCK inhibitor H1152, which largely diminished the attachment rates of tumor cells to levels comparable to those induced by simvastatin. Further studies concentrated on simvastatin doses of 32 and $64 \mu \mathrm{M}$. Since both tumor cell lines showed comparable adhesion and growth characteristics, ongoing 
A

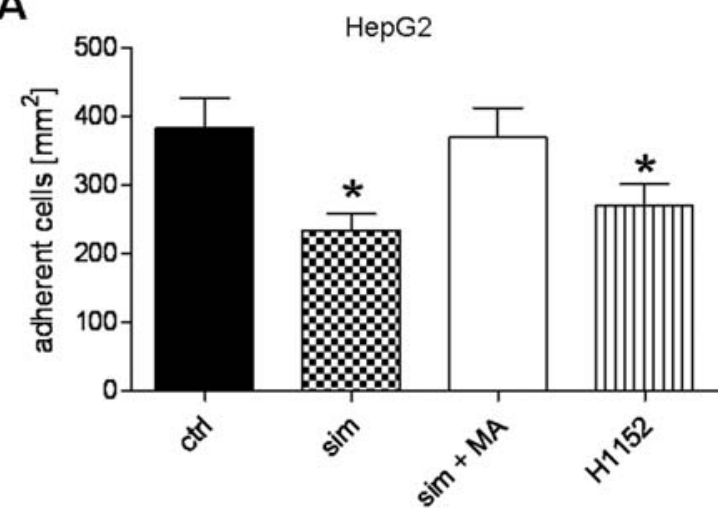

B

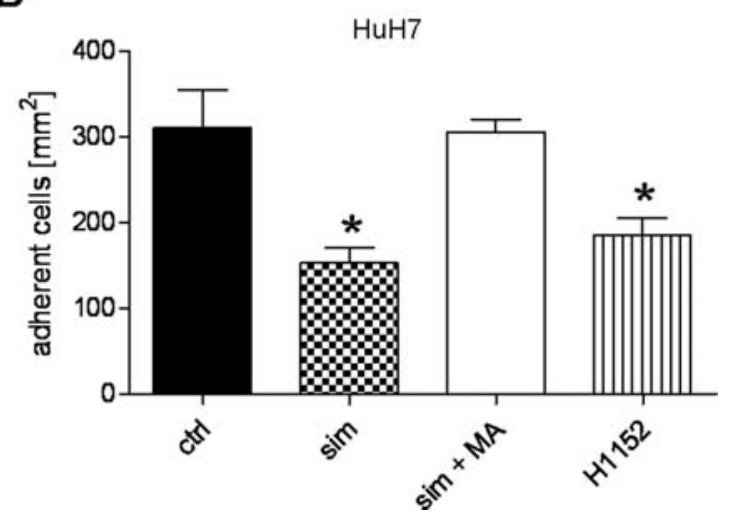

Figure 3. Effect of H1152 and mevalonate in combination with simvastatin on adhesion capacity of HepG2 and Huh7 cells to HUVECs. Adhesion was determined $48 \mathrm{~h}$ after treatment of HepG2 and Huh7 cells with simvastatin $(32 \mu \mathrm{M})$, simvastatin $(32 \mu \mathrm{M})$ in combination with mevalonate $(3.2 \mathrm{mM})$, with H1152 $(1 \mu \mathrm{M})$ or vehicle $(\operatorname{ctrl})$. Then, cells were added to HUVEC monolayers at a density of $0.5 \times 10^{6}$ cell/well for $60 \mathrm{~min}$. Non-adherent cells were washed off and adherent cells were fixed and counted in five different fields $\left(5 \times 0.25 \mathrm{~mm}^{2}\right)$ using a phase contrast microscopy. Data are given as the mean \pm SEM. Representative figure from one out of six experiments is shown ( ${ }^{*} \mathrm{p}<0.05$ vs. $\left.\mathrm{ctrl}\right)$.

experiments have been restricted to HepG2 as the representative cell line.

Simvastatin modulates the integrin expression pattern. Adhesion relevant integrin receptors were analyzed next. $B 1$ was expressed in both cell lines and decreased when simvastatin was applied for 48 or $72 \mathrm{~h}$. 33 was also expressed in HCC but decreased significantly when simvastatin was applied for 48 or 72 h. $\alpha 2$ expression was also diminished in HCC after simvastatin application (Fig. 4, representative for HepG2).

Functionality of integrins $\beta 1$ and $\beta 3$. Tumor cells were preincubated with antibodies against $\beta 1$ and $\beta 3$ integrins and subsequently allowed to attach to endothelial monolayer. The adhesion rates of both cell lines significantly declined following B1-receptor blockade as compared with untreated controls (Fig. 5). B3-receptor blockade slightly reduced the adhesion rates of tumor cells but these changes were not significant (data not shown).

Simvastatin modifies the ROCK activity. Next, the expression status of Rho/Rho-kinase and myosin phosphatase targeting
A

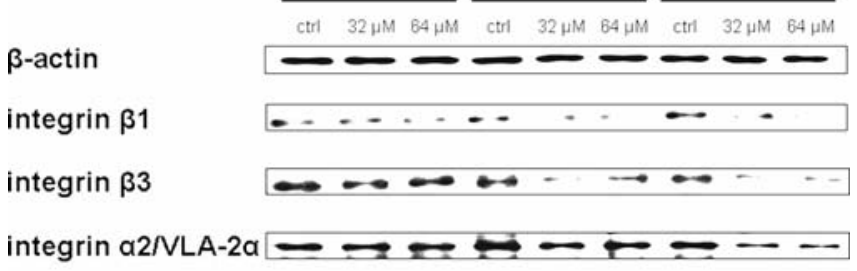

B

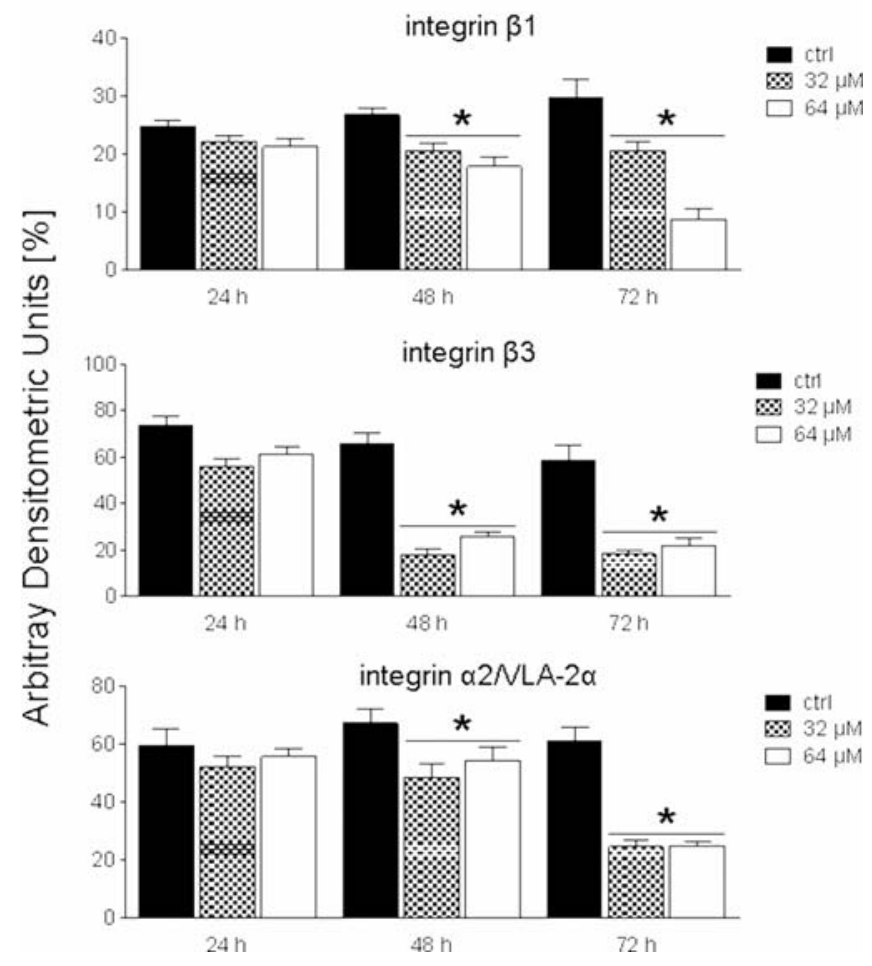

Figure 4. Analysis of $\beta 1, \beta 3$ and $\alpha 2$ integrin expressions using Western blot. HepG2 and Huh7 cells were treated with different doses of simvastatin ( 0 , 32 and $64 \mu \mathrm{M}$ ) for 24,48 and $72 \mathrm{~h}$ or remained untreated (ctrl). (A) Cell lysates were analyzed by specific antibodies as denoted in Materials and methods. $\beta$-actin served as internal loading control. Representative gel from 3 experiments is shown. (B) The intensity of each band of Western blot was determined and the ratio of each integrin and $\beta$-actin was calculated for each treatment $\left({ }^{*} \mathrm{p}<0.05\right.$ vs. ctrl).

subunit, Thr ${ }^{696}$-MYPT1, a marker for Rho-kinase activity, were determined. Western blot analysis for ROCK showed that ROCK was suppressed by simvastatin treatment. Additionally, simvastatin diminished Rho-kinase activity as demonstrated by reduced phosphorylation of MYPT and induced significant reduction of $\beta 1, \beta 3$ and $\alpha 2$ integrin expression (Fig. 4 and 6).

\section{Discussion}

The present study showed that simvastatin effectively downregulated tumor cell growth and adhesion capacity of HCC cells to endothelium and that these effects were associated with the decreased expression of $\beta 1, \beta 3$ and $\alpha 2$ integrins. These changes were in parallel to the level of relative protein expression of ROCK and its activity as shown by reduced phosphorylation of its substrate MYPT, suggesting that the 

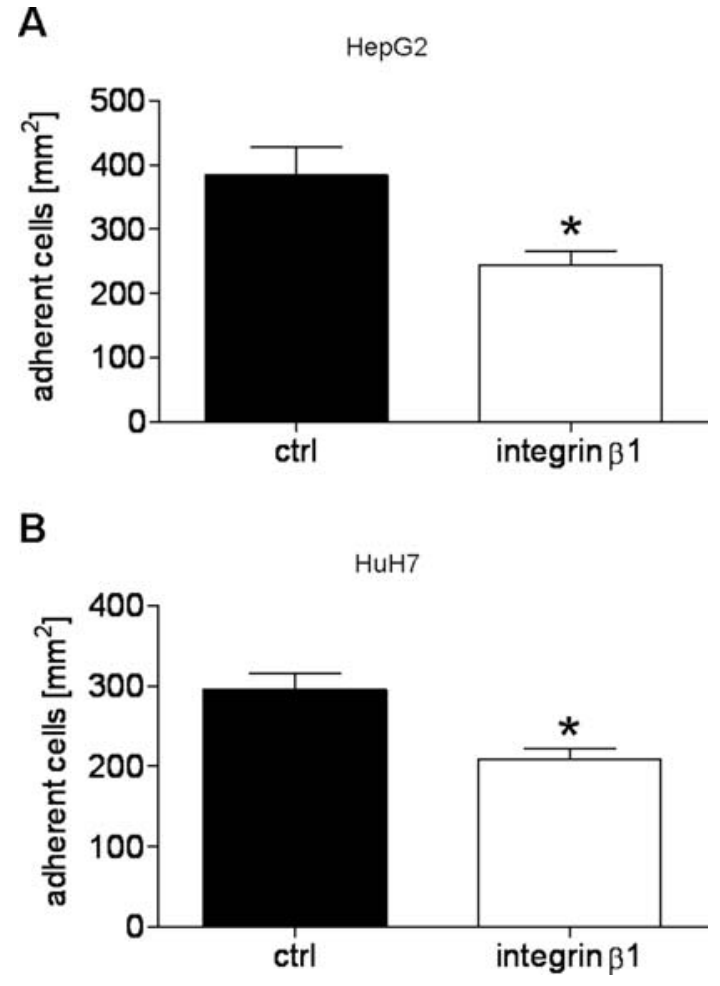

Figure 5. Analysis of the $\beta 1$ integrin functionality. Integrins $\beta 1$ was blocked by monoclonal antibodies and then adhesion of HepG2 and Huh7 cells to endothelium was determined. Controls (ctrl) remained untreated. Cells were added to HUVEC monolayers at a density of $0.5 \times 10^{6}$ cell/well for $60 \mathrm{~min}$. Non-adherent cells were washed off and adherent cells were fixed and counted in five different fields $\left(5 \times 0.25 \mathrm{~mm}^{2}\right)$ using a phase contrast microscopy. Data are given as the mean \pm SEM. Representative figure from one out of six experiments is shown ( ${ }^{*} \mathrm{p}<0.05$ vs. ctrl).

activation of ROCK is involved in the carcinogenic processes in HCC. The adhesion of tumor cells to vascular endothelium, subsequent disruption of the basement membrane and invasion of tumor cells into the host tissue are crucial steps in metastasis of cancer cells (15). Thus, the inhibitory potential of simvastatin could counteract metastasis of HCC and recurrence by suppressing tumor transmigration and consequently its progression.

Statins have been described to alter numerous cellular mechanisms. In vitro and in vivo studies showed that statins inhibit tumor cell growth, induce apoptosis, inhibit angiogenesis and impair the metastatic process (16). Although simvastatin has been demonstrated to modulate the pathogenesis of many cancer types by inhibiting tumor cell growth dynamics, data on simvastatin induced effects on hepatocellular carcinoma are sparse $(11,17,18)$. The present in vitro model reveals that simvastatin significantly influenced both the cell growth and adhesion behaviour of human hepatocellular carcinoma cells HepG2 and Huh7. Interestingly, treatment of HCC cells with simvastatin for 2 or 3 days was necessary to significantly reduce cell growth, whereas adhesion was reduced already after $24 \mathrm{~h}$ treatment with simvastatin. The reason for this is not clear. Previous studies point also to the HMG-CoA reductase inhibitors pravastatin or fluvastatin, which inhibited hepatocellular carcinoma cell proliferation and induced apoptosis (19). Also in rat HCC models, both compounds demonstrated beneficial effects, since they
A

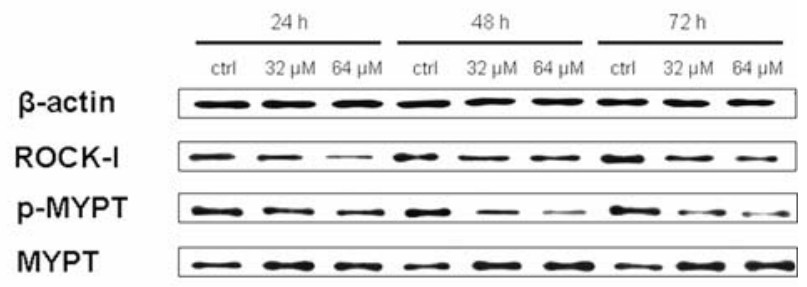

B
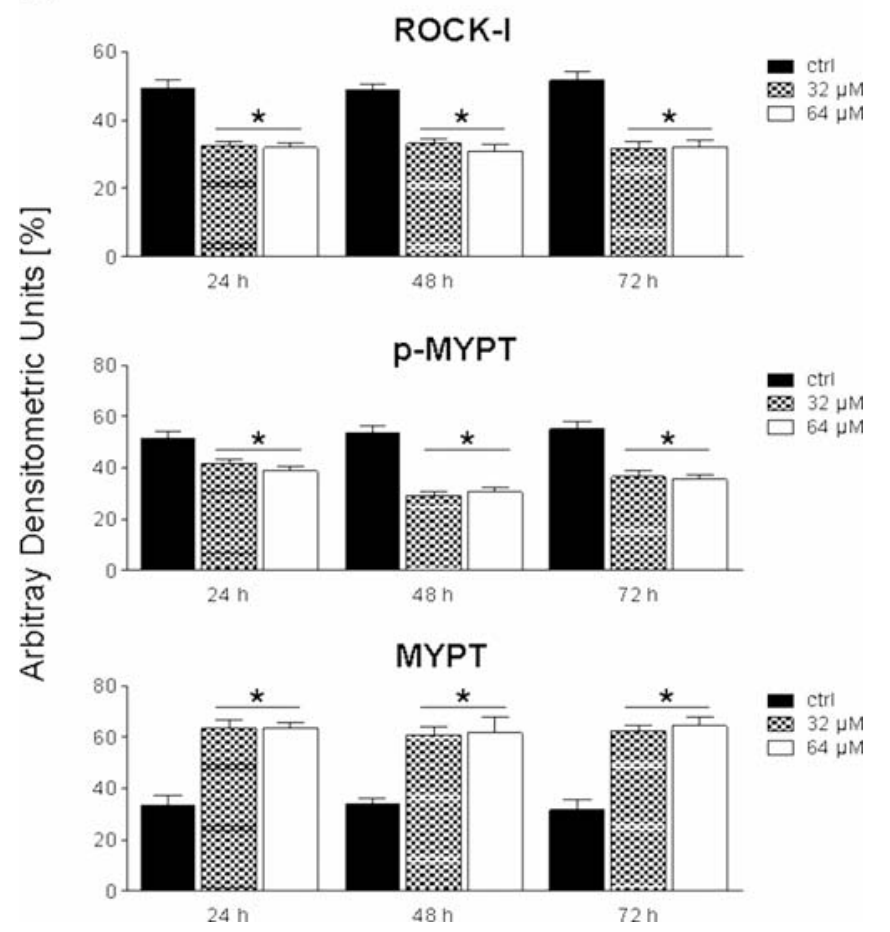

Figure 6. Simvastatin modifies the expression of ROCK-I and MYPT as well as MYPT phosphorylation. HepG2 and Huh7 cells were treated with different doses of simvastatin $(0,32$ and $64 \mu \mathrm{M})$ for 24,48 and $72 \mathrm{~h}$ or remained untreated (ctrl). (A) Cell lysates were analysed by specific antibodies as denoted in Materials and methods. B-actin served as internal loading control. One representative experiment of three is shown. In (B), densitometric measurements after normalization to $B$-actin staining are plotted, ctrl denotes vehicle treatment, 32 and $64 \mu \mathrm{M}$ denote simvastatin treatment with those doses $\left({ }^{*} \mathrm{p}<0.05 \mathrm{vs}\right.$. ctrl, representative gel from 3 experiments is shown).

inhibited the neoplastic development, cancer progression and improved survival (20-22). As statins are widely used in patients with hypercholesterolemia, the cancer risk and recurrence among statin users versus non-users is gaining increasing interest. Indeed, pravastatin prolonged the survival of patients with advanced HCC, with enhanced median survival from 9 to 18 months (23). Recently it has been reported that combined therapy of chemoembolization and pravastatin improved survival of patients with advanced HCC compared with patients receiving only chemoembolization (24). Combined therapy of leucovorin with simvastatin exerted promising anti-tumor activity in metastatic colorectal cancer patients (25). Thus, the most attractive application of statins will probably be as part of multidrug therapy.

To analyze the underlying biological mechanisms in simvastatin-induced $\mathrm{HCC}$ cell reduction, integrin receptor expression was evaluated, since integrins play a decisive role 
in tumor metastasis by mediating tumor cell targeting, arrest, adhesion and migration (26). Integrin $B 1$ subunit has been reported to be expressed on the surface of HCC cells and involved in HCC chemotaxis $(27,28)$. Moreover, $B 1$ integrin overexpression may protect hepatoma cells from apoptosis and contribute to chemotherapy resistance in HCC (29). In the current study, simvastatin reduced $B 1$ expression. Furthermore, blocking studies using the functional anti-integrin $\beta 1$ antibody resulted in strongly decreased adhesion of tumor cells to HUVECs revealing the functional impact of this integrin on adhesive capacity of tumor cells. Increased B3 integrin expression was associated with tumorigenesis and metastasis of HCC (30). Down-regulation of osteopontin inhibited HCC cell growth, tumorigenicity and lung metastasis, effects accompanied by suppressed expression of $\alpha \mathrm{v}, \beta 1$ and B3 integrins (30). Simvastatin reduced $B 3$ integrin expression accompanied by reduced tumor cell growth and adhesion to endothelium. We also found a strong reduction of integrin $\alpha 2$ after simvastatin pre-treatment of HCC cells. $\alpha 2$ integrin expression has been previously detected on HCC cells (27). Inhibition of $\alpha 1, \alpha 2$ and $\beta 1$ integrins significantly inhibited HCC cell migration induced by several growth factors (31). Expression levels of many different integrins are altered during cancer progression. Carcinogenesis of hepatocytes is also associated with a switch of integrin expression including an increase in $\alpha 2 \beta 1$ expression (32). Based on our results and reports of others, we conclude that tumor development might be caused by enhanced expression of certain integrin subtypes. However, we speculate that simvastatin reduced expression of integrins $\beta 1, \beta 3$ and $\alpha 2$ resulted in diminished adhesion capacity of HepG2 and Huh7 tumor cells.

The molecular mode of action of simvastatin in the modulation of HCC progression is not clear. Previous studies have identified numerous mediators of the carcinogenic processes involved in HCC. The Rho-kinases (ROCKs) are downstream effectors of Rho, a member of the Rho family small guanosine triphosphatases. Rho/ROCK pathway is involved in many aspects of cell motility including cell migration (33). Rat hepatoma cell transmigration through a cultured mesothelial cell monolayer is Rho/ROCK dependent (34). In line with these results, ROCK inhibition in vitro and in vivo resulted in reduced cell motility and intrahepatic metastatic dissemination of HCC cells (34-36). Recently, overexpression of ROCK was frequently found in primary HCCs and correlated with the presence of tumor microsatellite formation (10). Knockout of ROCK in HCC cells markedly inhibited myosin phosphatase phosphorylation and cell migration and invasion in vivo and in vitro (10). These findings are in line with our results showing that ROCK expression and MYPT phosphorylation are frequently detectable in HCC. Simvastatin has the potential to reduce the activities of the Rhoassociated protein kinases (ROCKs/ROCK1 and ROCK2) $(37,38)$. However, its role in HCC has not been described previously within this context. Our study demonstrates that simvastatin inhibits ROCK expression as well as its activity, since MYPT phosphorylation is down-regulated in HCC, an effect accompanied by reduced tumor cell growth and adhesion to endothelium (Figs. 1-3 and 6).

In conclusion, ROCK activation plays an important role in the carcinogenesis of HCC, since its inhibition by simvas- tatin may be associated with reduced tumor cell growth, adhesive capacity to endothelium and integrin expression. Hence, our results demonstrate the anti-carcinogenic and beneficial role of simvastatin in our HCC cell model and suggest that simvastatin may represent an attractive candidate for therapeutic intervention.

\section{Acknowledgements}

We thank Kerstin Wilhelm for outstanding technical assistance. We thank Karen Nelson for her generous help with the HUVECs.

\section{References}

1. Jemal A, Siegel R, Ward E, Hao Y, Xu J and Thun MJ: Cancer statistics. CA Cancer J Clin 59: 225-249, 2009.

2. Ferlay J, Autier P, Boniol M, Heanue M, Colombet M and Boyle P: Estimates of the cancer incidence and mortality in Europe in 2006. Ann Oncol 18: 581-592, 2007.

3. Kamangar F, Dores GM and Anderson WF: Patterns of cancer incidence, mortality, and prevalence across five continents: defining priorities to reduce cancer disparities in different geographic regions of the world. J Clin Oncol 24: 2137-2150, 2006.

4. Roayaie S, Schwartz JD, Sung MW, Emre SH, Miller CM, Gondolesi GE, Krieger NR and Schwartz ME: Recurrence of hepatocellular carcinoma after liver transplant: patterns and prognosis. Liver Transpl 10: 534-540, 2004.

5. Morris-Stiff G, Gomez D, de Liguori CN and Prasad KR: Surgical management of hepatocellular carcinoma: is the jury still out? Surg Oncol 18: 298-321, 2009.

6. Goldstein JL and Brown MS: Regulation of the mevalonate pathway. Nature 343: 425-430, 1990.

7. Fromigue O, Hay E, Modrowski D, Bouvet S, Jacquel A, Auberger P and Marie PJ: RhoA GTPase inactivation by statins induces osteosarcoma cell apoptosis by inhibiting p42/p44MAPKs-Bcl-2 signaling independently of BMP-2 and cell differentiation. Cell Death Differ 13: 1845-1856, 2006.

8. Riganti C, Doublier S, Costamagna C, Aldieri E, Pescarmona G, Ghigo D and Bosia A: Activation of nuclear factor-kappa B pathway by simvastatin and RhoA silencing increases doxorubicin cytotoxicity in human colon cancer HT29 cells. Mol Pharmacol 74: 476-484, 2008.

9. Charni F, Friand V, Haddad O, Hlawaty H, Martin L, Vassy R, Oudar O, Gattegno L, Charnaux N and Sutton A: Syndecan-1 and syndecan-4 are involved in RANTES/CCL5-induced migration and invasion of human hepatoma cells. Biochim Biophys Acta 1790: 1314-1326, 2009.

10. Wong CC, Wong CM, Tung EK, Man K and Ng IO: Rho-kinase 2 is frequently overexpressed in hepatocellular carcinoma and involved in tumor invasion. Hepatology 49: 1583-1594, 2009.

11. Ghosh-Choudhury N, Mandal CC, Ghosh-Choudhury N and Ghosh-Choudhury G: Simvastatin induces derepression of PTEN expression via NFkappaB to inhibit breast cancer cell growth. Cell Signal 22: 749-758, 2010.

12. Cho SJ, Kim JS, Kim JM, Lee JY, Jung HC and Song IS: Simvastatin induces apoptosis in human colon cancer cells and in tumor xenografts, and attenuates colitis-associated colon cancer in mice. Int J Cancer 123: 951-957, 2008.

13. Sekine Y, Furuya Y, Nishii M, Koike H, Matsui H and Suzuki K: Simvastatin inhibits the proliferation of human prostate cancer PC-3 cells via down-regulation of the insulin-like growth factor 1 receptor. Biochem Biophys Res Commun 372: 356-361, 2008.

14. Hynes RO: Integrins: versatility, modulation, and signaling in cell adhesion. Cell 69: 11-25, 1992.

15. Yam JW, Tse EY and Ng IO: Role and significance of focal adhesion proteins in hepatocellular carcinoma. J Gastroenterol Hepatol 24: 520-530, 2009.

16. Hindler K, Cleeland CS, Rivera E and Collard CD: The role of statins in cancer therapy. Oncologist 11: 306-315, 2006.

17. Newman A, Clutterbuck RD, Powles RL and Millar JL: Selective inhibition of primary acute myeloid leukaemia cell growth by simvastatin. Leukemia 8: 2023-2029, 1994. 
18. Yang YC, Huang WF, Chuan LM, Xiao DW, Zeng YL, Zhou DA Xu GQ, Liu W, Huang B and Hu Q: In vitro and in vivo study of cell growth inhibition of simvastatin on chronic myelogenous leukemia cells. Chemotherapy 54: 438-446, 2008.

19. Sutter AP, Maaser K, Hopfner M, Huether A, Schuppan D and Scherubl H: Cell cycle arrest and apoptosis induction in hepatocellular carcinoma cells by HMG-CoA reductase inhibitors. Synergistic antiproliferative action with ligands of the peripheral benzodiazepine receptor. J Hepatol 43: 808-816, 2005.

20. Paragh G, Kertai P, Kovacs P, Paragh G Jr, Fulop P and Foris G: HMG CoA reductase inhibitor fluvastatin arrests the development of implanted hepatocarcinoma in rats. Anticancer Res 23: 3949-3954, 2003.

21. Taras D, Blanc JF, Rullier A, Dugot-Senant N, Laurendeau I, Vidaud $\mathrm{M}$ and Rosenbaum J: Pravastatin reduces lung metastasis of rat hepatocellular carcinoma via a coordinated decrease of MMP expression and activity. J Hepatol 46: 69-76, 2007.

22. Kawata S, Kakimoto H, Ishiguro H, Yamasaki E, Inui $\mathrm{Y}$ and Matsuzawa Y: Effect of pravastatin, a potent 3-hydroxy-3methylglutaryl-coenzyme A reductase inhibitor, on survival of AH130 hepatoma-bearing rats. Jpn J Cancer Res 83: 1120-1123, 1992.

23. Kawata S, Yamasaki E, Nagase T, Inui Y, Ito N, Matsuda Y, Inada M, Tamura S, Noda S, Imai Y and Matsuzawa Y: Effect of pravastatin on survival in patients with advanced hepatocellular carcinoma. A randomized controlled trial. Br J Cancer 84: 886-891, 2001

24. Graf H, Jungst C, Straub G, Dogan S, Hoffmann RT, Jakobs T, Reiser M, Waggershauser T, Helmberger T, Walter A, Walli A, Seidel D, Goke B and Jungst D: Chemoembolization combined with pravastatin improves survival in patients with hepatocellular carcinoma. Digestion 78: 34-38, 2008

25. Lee J, Jung KH, Park YS, Ahn JB, Shin SJ, Im SA, Oh DY, Shin DB, Kim TW, Lee N, Byun JH, Hong YS, Park JO, Park SH, Lim HY and Kang WK: Simvastatin plus irinotecan, 5-fluorouracil, and leucovorin (FOLFIRI) as first-line chemotherapy in metastatic colorectal patients: a multicenter phase II study. Cancer Chemother Pharmacol 64: 657-663, 2009.

26. Desgrosellier JS and Cheresh DA: Integrins in cancer: biological implications and therapeutic opportunities. Nat Rev Cancer 10: 9-22, 2010.

27. $\mathrm{Fu} \mathrm{BH}, \mathrm{Wu} \mathrm{ZZ}$ and Qin J: Effects of integrins on laminin chemotaxis by hepatocellular carcinoma cells. Mol Biol Rep 37: 1665-1670, 2009.

28. Song G, Luo Q, Qin J, Wang B and Cai S: Expression of integrin beta1 and its roles on adhesion between different cell cycle hepatocellular carcinoma cells (SMMC-7721) and human umbilical vein endothelial cells. Colloids Surf B Biointerfaces 34: $247-252,2004$
29. Zhang H, Ozaki I, Mizuta T, Matsuhashi S, Yoshimura T, Hisatomi A, Tadano J, Sakai T and Yamamoto K: Beta 1integrin protects hepatoma cells from chemotherapy induced apoptosis via a mitogen-activated protein kinase dependent pathway. Cancer 95: 896-906, 2002.

30. Zhao J, Dong L, Lu B, Wu G, Xu D, Chen J, Li K, Tong X, Dai J, Yao S, Wu M and Guo Y: Down-regulation of osteopontin suppresses growth and metastasis of hepatocellular carcinoma via induction of apoptosis. Gastroenterology 135: 956-968, 2008.

31. Yang C, Zeisberg M, Lively JC, Nyberg P, Afdhal N and Kalluri R: Integrin alpha1beta1 and alpha2beta1 are the key regulators of hepatocarcinoma cell invasion across the fibrotic matrix microenvironment. Cancer Res 63: 8312-8317, 2003.

32. Kawakami-Kimura N, Narita T, Ohmori K, Yoneda T, Matsumoto K, Nakamura T and Kannagi R: Involvement of hepatocyte growth factor in increased integrin expression on HepG2 cells triggered by adhesion to endothelial cells. Br J Cancer 75: 47-53, 1997.

33. Riento K and Ridley AJ: Rocks: multifunctional kinases in cell behaviour. Nat Rev Mol Cell Biol 4: 446-456, 2003.

34. Itoh K, Yoshioka K, Akedo H, Uehata M, Ishizaki T and Narumiya S: An essential part for Rho-associated kinase in the transcellular invasion of tumor cells. Nat Med 5: 221-225, 1999.

35. Takamura M, Sakamoto M, Genda T, Ichida T, Asakura H and Hirohashi S: Inhibition of intrahepatic metastasis of human hepatocellular carcinoma by Rho-associated protein kinase inhibitor Y-27632. Hepatology 33: 577-581, 2001.

36. Wang DS, Dou KF, Li KZ and Song ZS: Enhancement of migration and invasion of hepatoma cells via a Rho GTPase signaling pathway. World J Gastroenterol 10: 299-302, 2004.

37. Ma T, Zhao Y, Kwak YD, Yang Z, Thompson R, Luo Z, Xu H and Liao FF: Statin's excitoprotection is mediated by sAPP and the subsequent attenuation of calpain-induced truncation events, likely via rho-ROCK signaling. J Neurosci 29: 11226-11236, 2009.

38. Relja B, Lehnert M, Seyboth K, Bormann F, Hohn C, Czerny C, Henrich D and Marzi I: Simvastatin reduces mortality and hepatic injury after hemorrhage/resuscitation in rats. Shock 34 : 46-54, 2010. 